\title{
Prevalence of Metabolic Syndrome in Young Patients with ST-Elevation Myocardial Infarction
}

\author{
Tugba Kemaloglu Öz, Nazmiye Özbilgin'1, Aylin Sungurr', Elif Gülsah Bas, Ahmet Zengin'1, Tayfun Gürol, Özer Soylu, Bahadir Dagdeviren \\ Department of Cardiology, Faculty of Medicine, Bahcesehir University, 'Department of Cardiology, Dr. Siyami Ersek Thoracic and Cardiovascular Surgery Training and \\ Research Center, Istanbul, Turkey
}

\section{Abstract}

Background: Atherosclerotic cardiovascular disease influences young patients as well as the elderly. A large proportion of patients with coronary artery disease (CAD) have metabolic syndrome (MS), although the frequency and association of its different components are not clear. To the best of our knowledge, there is no any study about the prevalence of MS among young patients with ST-elevation myocardial infarction (STEMI). We sought to determine the prevalence of MS in patients below 46 years of age who presented with STEMI and underwent primary percutaneous coronary intervention. Methods: In the present prospective study, 141 consecutive patients with STEMI $<46$ years of age admitted to intensive coronary care unit. STEMI was defined according to the ESC guidelines for the management of acute myocardial infarction in patients presenting with ST-segment elevation. All patients were grouped presence of MS. In the second step, the components of MS were analyzed, excluding patients with diabetes mellitus (DM). Results: The total prevalence of MS was $46.8 \%(n=66)$. In MS group, the most frequent component of MS was low high-density lipoprotein (HDL) levels (84.8\%), followed by elevated triglycerides (TGs) (78.1\%). A total of 121 patients did not have DM and 51 (42.1\%) of these patients presented with MS. Conclusions: The prevalence of MS in young patients with STEMI is high. Low HDL cholesterol (HDLc) concentrations and high TG levels are cardiovascular risk factors, regardless of low-density lipoprotein cholesterol levels and they are found too often in our study. These results highlight the need to implement preventative strategies for reducing overall cardiovascular risk in young patients as well as elderly.

Keywords: Acute coronary syndrome, coronary artery disease, metabolic syndrome, ST-elevation myocardial infarction, young patients

\section{INTRODUCTION}

Metabolic syndrome (MS) is a clinical and biological entity of lipid and nonlipid factors of metabolic origin, which places subjects at risk for cardiovascular and cerebrovascular diseases. It has been previously defined by $3^{\text {rd }}$ Report of the National Cholesterol Education Program Expert Panel on Detection, Evaluation, and Treatment of High Blood Cholesterol in Adults (NCEP ATP-III). ${ }^{[1]}$

Worldwide, coronary artery disease (CAD) is the single most frequent cause of death. ${ }^{[2]}$ The atherosclerotic cardiovascular disease is a chronic disorder developing insidiously, and it remains as the major cause of premature death. Importantly, evidence revealing that increased cardiovascular risk starts to develop at a very young age has accumulated over the past decades. ${ }^{[3]}$ Acute myocardial infarction (AMI) among adults aged $<46$ is unusual, comprising $2 \%-10 \%$ of all cases. ${ }^{[4]}$

Some studies have analyzed the prevalence of MS in patients with the acute coronary syndrome (ACS) but with mix populations

\begin{tabular}{|l|l|}
\hline \multicolumn{3}{|c|}{ Access this article online } \\
\hline Quick Response Code: & Website: \\
& \\
http://www.ijcva.com
\end{tabular}

including both ST-elevation myocardial infarction (STEMI) and non-STEMI (NSTEMI), also all age groups. ${ }^{[5-7]}$

To the best of our knowledge, this is the first study to determine the prevalence of the MS in patients $<46$ years of age who presented with STEMI and underwent primary percutaneous coronary intervention (PCI).

\section{Methods}

In the present prospective study, 141 consecutive patients with STEMI $<45$ years of age admitted to intensive coronary care unit. STEMI was defined according to the ESC guidelines

Address for correspondence: Dr. Tugba Kemaloglu Öz, Kadiköy, E5 Üzeri 23, Nisan Sok Merdivenköy No: 17, 34732 Kadiköy, Istanbul, Turkey. E-mail: Tugbakemalogluoz@gmail.com.

This is an open access journal, and articles are distributed under the terms of the Creative Commons Attribution-NonCommercial-ShareAlike 4.0 License, which allows others to remix, tweak, and build upon the work non-commercially, as long as appropriate credit is given and the new creations are licensed under the identical terms.

For reprints contact: reprints@medknow.com

How to cite this article: Öz TK, Özbilgin N, Sungur A, Bas EG, Zengin A, Gürol T, et al. Prevalence of metabolic syndrome in young patients with ST-elevation myocardial infarction. Int J Cardiovasc Acad 2018;4:53-8. 
for the management of AMI in patients presenting with ST-segment elevation. ${ }^{[8]}$

For the diagnosis of MS at baseline, we used the NCEP-ATP III criteria. MS was defined as having three or more of following criteria: ${ }^{[1]}$

1. Abdominal obesity: Waist circumference (WC) $>102 \mathrm{~cm}$ for men and $>88 \mathrm{~cm}$ for women

2. Elevated Triglycerides (TGs) of $\geq 150 \mathrm{mg} / \mathrm{dl}$

3. Low high-density lipoprotein (HDL) $<40 \mathrm{mg} / \mathrm{dl}$ for men and $<50 \mathrm{mg} / \mathrm{dl}$ for women

4. Elevated blood pressure $\geq 130 / 85 \mathrm{mmHg}$

5. Elevated fasting blood glucose $\geq 110 \mathrm{mg} / \mathrm{dl}$.

Patients who were not diagnosed with STEMI or had incomplete data or who used antilipidemic drugs were excluded from the study.

All patients underwent coronary angiography and results were analyzed. A coronary lesion was defined as significant if at least $70 \%$ of lumen diameter was reduced, except culprit lesion.

All patients were grouped first based on the presence of MS and then grouped again after excluding patients with diabetes mellitus (DM).

Demographic and clinical data were obtained from histories: age, sex, smoking, alcohol consumption, family history (premature coronary heart disease at 55 and 65 years of age in male and female first-degree relatives, respectively), and previous lipid-lowering treatment.

The diagnosis of DM was made by a fasting blood glucose level of $125 \mathrm{mg} / \mathrm{dl}$ or a history of DM, including those treated with diet control, oral medications, or insulin.

Blood pressure was determined in both arms after a 5 -min rest. Patients were diagnosed with high blood pressure for an average (of 3 values) blood pressure during admission $\geq 130 / 85 \mathrm{~mm} \mathrm{Hg}$ or if a previous diagnosis of hypertension had been made and/or treatment had already been prescribed at the time of admission.

The heights and weights of all patients were taken before discharge. The weight in kilograms $(\mathrm{kg})$ was measured using a calibrated scale with capacity for $180 \mathrm{~kg}$ and increments of $100 \mathrm{~g}$. The height, in meters, was measured using anthropometric scale. The body-mass index (BMI) was calculated using the formula: Body weight $(\mathrm{kg}) / \mathrm{heigt}^{2}\left(\mathrm{~m}^{2}\right)$. We used the international classes of BMI: Obesity (BMI $\geq 30 \mathrm{~kg} / \mathrm{m}^{2}$ ), overweight (BMI $25-29.9 \mathrm{~kg} / \mathrm{m}^{2}$ ), normal (BMI 18.5-24.9 kg/m²), and underweight (BMI $<18.5 \mathrm{~kg} / \mathrm{m}^{2}$ ).

Waist and hip circumferences (HC) were recorded. WCs were measured at the level midway between the lowest rib and the iliac crest, the thinnest part of abdomen and $\mathrm{HC}$ were measured at the maximum circumference between the hips and buttocks.

Plasma samples were obtained after at least $12 \mathrm{~h}$ of fasting. Total cholesterol and TG levels were measured using an automated enzyme analyzer, and low-density lipoprotein (LDL) concentrations were calculated using the Friedewald formula whenever plasma TG concentrations were $<400 \mathrm{mg} / \mathrm{dl}$ (Advia Systems, Siemens, Australia). D-dimer was estimated using automatic latex immunoassay (HemosIL ${ }^{\mathrm{TM}}$, Instrumentation Laboratory, USA). Fibrinogen-C was measured according to the method of Class (HemosIL ${ }^{\mathrm{R}}$, Instrumentation Laboratory, USA). C-reactive protein was measured using latex-enhanced immunotubidimetry (Advia System, Siemens, Australia).

Transthoracic echocardiography was performed in all patients before discharge.

Quantitative variables were expressed as a mean \pm standard deviation, median (interquartile range) and qualitative variables as absolute and relative frequencies. Normally distributed data were analyzed using the Student's $t$-test to compare means; otherwise, the Mann-Whitney U-test (MWU) was used. The Chi-square test was used to analyze differences between qualitative variables. A two-sided $P<0.05$ was used as a cut-off for statistical significance. Results of $\mathrm{x}^{2}$ test were expressed as Chi-square (degrees of freedom, sample size $)=$ Pearson's Chi-square value, $P$ value. Results of Student's $t$-test were expressed as $t$ (degrees of freedom) $=t$ value, $P$ value, $95 \%$ confidence interval $(\mathrm{CI})$. Results of MWU-test were expressed as MWU value, $P$ value. The SPSS software version 17.0 (SPSS science, Chicago, IL, USA) was used for statistical analyses.

Institutional Review Board approved this study for research, and all patients gave written informed consent before the study.

\section{ResULTS}

The present study included a total of 141 consecutive patients with STEMI. The majority of the admitted patients were men $(87.9 \%)$, and the mean age was $38.3 \pm 4.6$, ranging from 26 to 45 years. Table 1 shows the demographic and clinical characteristics of the patients stratified by MS status, and we compared the baseline characteristics of patients with and without MS. BMI was significantly higher in the MS group $\left(\chi^{2}[2,139]=19.17, P<0.001\right)$. Waist and HC were also significantly higher in the MS group $(t[138]=-4.24, P<0.001$, $95 \%$ CI $[-10.39,-3.79]$ and $t[138]=-3.24, P<0.001,95 \%$ CI $(-6.91,-1.67)$; respectively). Systolic and diastolic blood pressures were significantly elevated in the MS group $(t[137]=-3.61$, $P<0.001,95 \%$ CI $[-14.78,-4.33]$ and $t[137]=-3.78, P<0.001$, $95 \% \mathrm{CI}[-9.57,-2.99]$; respectively). Fasting plasma glucose was significantly higher in the MS group; $t(138)=-3.92, P<0.001$, $95 \%$ CI $(-46.26,-15.23)$. Total cholesterol and TG showed significantly higher levels in the MS group $(t[138]=-2.23$, $P=0.02,95 \%$ CI $[-27.88,-1.66]$ and $t[136]=-6.19, P<0.001$, $95 \%$ CI [ $-147.08,-75.87]$, respectively). Fibrinogen was also found to be significantly higher in the patients with MS; $t(128)=-2.17, P=0.01,95 \%$ CI $(-69.49,-3.3)$. However, HDL cholesterol (HDLc) and LDL cholesterol (LDLc) levels did not significantly differ between the groups. 


\begin{tabular}{|c|c|c|c|}
\hline \multicolumn{4}{|c|}{$\begin{array}{l}\text { Table } 1 \text { Demographic and clinical characteristics of the } \\
\text { patients stratified by metabolic syndrome status }\end{array}$} \\
\hline \multirow[t]{2}{*}{ Variable } & \multicolumn{2}{|c|}{ MS } & \multirow[t]{2}{*}{$P$} \\
\hline & $\begin{array}{c}\text { Positive } \\
(n=66: 46.8 \%)\end{array}$ & $\begin{array}{c}\text { Negative } \\
(n=75: 53.2 \%)\end{array}$ & \\
\hline Age (years) & $39.0 \pm 4.0$ & $37,7 \pm 5.1$ & 0.12 \\
\hline Men, $n(\%)$ & $55(83.3)$ & $69(92.0)$ & 0.11 \\
\hline Smoker, $n(\%)$ & $55(83.3)$ & $64(85.3)$ & 0.74 \\
\hline Alcohol consumer, $n(\%)$ & $12(18.2)$ & $6(8.1)$ & 0.07 \\
\hline Drug abuser, $n(\%)$ & $1(1.5)$ & $1(1.3)$ & 0.95 \\
\hline Family history, $n(\%)$ & $21(31.8)$ & $18(24.0)$ & 0.30 \\
\hline BMI $\left(\mathrm{kg} / \mathrm{m}^{2}\right), n(\%)$ & $29.3 \pm 4.1$ & $26.4 \pm 3.6$ & \\
\hline$<25$ & $11(16.7)$ & $28(37.3)$ & $<0.001$ \\
\hline $25-29.9$ & $22(34.8)$ & $36(48.0)$ & \\
\hline$>30$ & $32(49.2)$ & $11(14.7)$ & \\
\hline Waist circumference (cm) & $98.4 \pm 11.3$ & $91.5 \pm 8.3$ & $<0.001$ \\
\hline Hip circumference $(\mathrm{cm})$ & $105.3 \pm 8.5$ & $101.1 \pm 7.1$ & $<0.001$ \\
\hline \multicolumn{4}{|l|}{ Blood pressure (mmHg) } \\
\hline Systolic & $128.2 \pm 17.4$ & $118.6 \pm 13.5$ & $<0.001$ \\
\hline Diastolic & $78.2 \pm 11.4$ & $72.0 \pm 7.9$ & $<0.001$ \\
\hline $\begin{array}{l}\text { Fasting plasma } \\
\text { glucose }(\mathrm{mg} / \mathrm{dl})^{*}\end{array}$ & $47(113)$ & $14.2(94)$ & $<0.001$ \\
\hline Total cholesterol (mg/dl) & $196.5 \pm 39.8$ & $181.7 \pm 38.5$ & 0.02 \\
\hline LDL-C (mg/dl) & $117.7 \pm 31.5$ & $121.7 \pm 36.1$ & 0.50 \\
\hline HDL-C (mg/dl) & $35.1 \pm 11.8$ & $35.1 \pm 9.0$ & 0.99 \\
\hline Triglycerides (mg/dl)* & $107(190)$ & $62.2(110)$ & $<0.001$ \\
\hline $\mathrm{CRP}(\mathrm{mg} / \mathrm{dl})^{*}$ & $3.4(4.2)$ & $1.0(3.4)$ & 0.15 \\
\hline Fibrinogen (mg/dl) & $389.3 \pm 110.5$ & $348.3 \pm 78.9$ & 0.01 \\
\hline D-dimer (ng/ml)* & $136.0(123.0)$ & $135.2(117.5)$ & 0.52 \\
\hline Ejection fraction (\%) & $51.7 \pm 8.6$ & $52.5 \pm 9.1$ & 0.60 \\
\hline
\end{tabular}

The total prevalence of MS using ATPIII criteria was $46.8 \%(n=66)$. In MS group, the most frequent component of MS was low HDL level ( $84.8 \%$ ), followed by elevated TG (78.1\%), elevated blood pressure (63.6\%), carbohydrate metabolism disorder (59.1\%) and in the last place, abdominal obesity (46.\%) [Figure 1]. We found no MS components in 11 patients (7.8\%). 15 patients with MS (22.7\%) had DM.

In total, MS was not found in $75(53.2 \%)$ patients. The most frequent component was among the patients without MS was low HDLc level (67.6\%), followed by elevated blood pressure $(25.7 \%)$, elevated TG $(23.0 \%)$, carbohydrate metabolism disorder (21.3\%), and abdominal obesity (8.0\%). Five patients without MS (6.7\%) had DM.

In this study, 121 patients did not have DM and 51 (42.1\%) of these patients presented with MS [Table 2]. The most prevalent component of MS was low HDLc (73.6\%), followed by elevated TG (45.5\%), elevated blood pressure (43.0\%), carbohydrate metabolism disorder $(30.6 \%)$ and, finally, abdominal obesity (23.1\%) [Figure 1]. In this substudy prevalence of alcohol consumption was significantly higher in patients with MS than patients without MS;

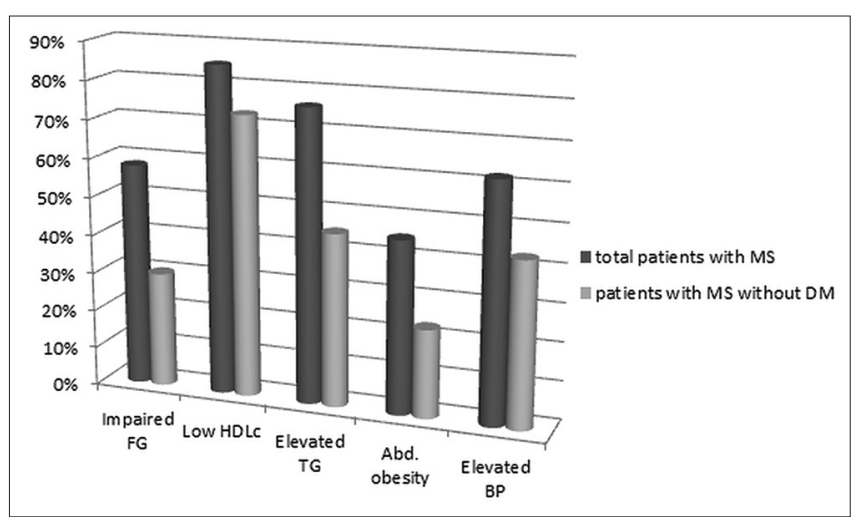

Figure 1: Distribution of metabolic syndrome criterias in all patients with metabolic syndrome and after excluding patients with DM. Abd: Abdominal, BP: Blood pressure, DM: Diabetes mellitus, FG: Fasting glucose, HDLc: High-density lipoprotein cholesterol, TG: Triglycerides

$\chi^{2}(1,120)=4.09, P=0.04$. BMI was higher in the MS group; $\chi^{2}(2,120)=15.33, P<0.001$. Waist and $\mathrm{HC}$ were also significantly higher in patients with MS $(t[119]=-3.53$, $P<0.001,95 \%$ CI $[-10.24,-2.88]$ and $t[119]=-2.57$, $P=0.01,95 \%$ CI $[-6.83,-0.88]$, respectively). Systolic and diastolic blood pressures were significantly elevated in the MS group $(t[118]=-3.94, P<0.001,95 \%$ CI $[-15.76,-5.21]$ and $t[118]=-3.72, P<0.001,95 \%$ CI $[-10.05,-3.07]$; respectively). Fasting plasma glucose was significantly higher in the MS group (MWU $=1046, P<0.001$ ). Total cholesterol showed significantly higher levels in patients with MS; $t(118)=-2.03, P=0.04,95 \%$ CI $(-28.78,-0.36)$. TG levels was significantly higher in the MS group (MWU $=636.5$, $P<0.001$ ). Fibrinogen was also found to be significantly higher in the patients with MS; $t(109)=-3.01, P<0.001$, $95 \%$ CI $(-84.97,-17.49)$.

When we assessed the most prevalent combination of ATPIII factors in the patients with MS, 12 patients (18.2\%) fulfilled the triad of low HDLc levels, elevated TG and carbohydrate metabolism disorder. The most prevalent tetrad was $(n=9,13.6 \%)$ low HDLc levels, elevated TG, carbohydrate metabolism disorder and elevated blood pressure. In the patients without DM the most prevalent triad of MS was low HDLc levels, elevated TG and elevated blood pressure $(n=10,19.6 \%)$. The most prevalent tetrad was found same in two groups.

Single-vessel involvement with left anterior descending artery (LAD), as the culprit lesion, was the most frequent presentation and followed by the circumflex artery and right coronary artery. Distribution of vascular lesions in patients with MS was compared to patients without MS, and no significant difference was observed among the groups.

\section{Discussion}

In the present prospective study, 141 consecutive patients with STEMI $<45$ years of age who were treated with primary PCI were evaluated. Only a few studies have evaluated the prevalence of MS, as defined by the nonmodified NCEP-ATP 


\begin{tabular}{|c|c|c|c|}
\hline \multicolumn{4}{|c|}{$\begin{array}{l}\text { Table 2: Demographic and clinical characteristics of the } \\
\text { patients stratified by metabolic syndrome status, after } \\
\text { excluding patients with diabetes mellitus }\end{array}$} \\
\hline \multirow[t]{2}{*}{ Variable } & \multicolumn{2}{|c|}{ MS } & \multirow[t]{2}{*}{$P$} \\
\hline & $\begin{array}{c}\text { Positive } \\
(n=51: 42.1 \%)\end{array}$ & $\begin{array}{c}\text { Negative } \\
(n=70: 57.9 \%)\end{array}$ & \\
\hline Age (years) & $38.3 \pm 4.1$ & $37.4 \pm 5.0$ & 0.35 \\
\hline Men, $n(\%)$ & $41(80.4)$ & $64(91.4)$ & 0.61 \\
\hline Alcohol consumer, $n(\%)$ & $10(19.6)$ & $5(7.2)$ & 0.04 \\
\hline Drug abuser, $n(\%)$ & $1(2.0)$ & $1(1.4)$ & 0.82 \\
\hline Family history, $n(\%)$ & $16(31.4)$ & $17(24.3)$ & 0.38 \\
\hline BMI $\left(\mathrm{kg} / \mathrm{m}^{2}\right), n(\%)$ & $28.9 \pm 4.0$ & $26.3 \pm 3.6$ & \\
\hline$<25$ & $10(20.0)$ & $28(40.0)$ & $<0.001$ \\
\hline $25-29.9$ & $17(34.0)$ & $32(45.7)$ & \\
\hline$>30$ & $23(46.0)$ & $10(14.3)$ & \\
\hline Waist circumference $(\mathrm{cm})$ & $97.7 \pm 12.0$ & $91.1 \pm 8.4$ & $<0.001$ \\
\hline Hip circumference $(\mathrm{cm})$ & $105.0 \pm 9.1$ & $101.2 \pm 7.3$ & 0.01 \\
\hline \multicolumn{4}{|l|}{ Blood pressure (mmHg) } \\
\hline Systolic & $128.5 \pm 16.3$ & $118.0 \pm 12.8$ & $<0.001$ \\
\hline Diastolic & $78.4 \pm 11.2$ & $71.8 \pm 8.0$ & $<0.001$ \\
\hline $\begin{array}{l}\text { Fasting plasma } \\
\text { glucose }(\mathrm{mg} / \mathrm{dl})^{*}\end{array}$ & $24.0(110.0)$ & $22.2(97.5)$ & $<0.001$ \\
\hline Total cholesterol (mg/dl) & $196.5 \pm 40.2$ & $181.9 \pm 37.8$ & 0.04 \\
\hline LDL-C (mg/dl) & $118.0 \pm 32.2$ & $122.0 \pm 36.0$ & 0.53 \\
\hline HDL-C (mg/dl)* & $9.0(36.0)$ & $13.0(34.5)$ & 0.52 \\
\hline Triglycerides $(\mathrm{mg} / \mathrm{dl})^{*}$ & $103.5(190.0)$ & $89.7(140.0)$ & $<0.001$ \\
\hline hsCRP $(\mathrm{mg} / \mathrm{dl})^{*}$ & $3.5(2.1)$ & $3.8(1.5)$ & 0.22 \\
\hline Fibrinojen (mg/dl) & $401.4 \pm 100.3$ & $350.2 \pm 78.9$ & $<0.001$ \\
\hline D-dimer (ng/ml)* & $106.0(110.0)$ & $119.0(115.5)$ & 0.59 \\
\hline Ejection fraction (\%) & $51.7 \pm 8.5$ & $52.9 \pm 8.6$ & 0.50 \\
\hline
\end{tabular}

*Values expressed as median (interquartile range). Values are mean $\pm \mathrm{SD}$ or $n(\%)$. BMI: Body mass index, CRP: C-reactive protein, DM: Diabetes mellitus, HDL-C: High-density lipoprotein cholesterol, LDL-C: Low-density lipoprotein cholesterol, SD: Standard deviation, MS: Metabolic syndrome

III criteria and to the best of our knowledge, there is not any study about the prevalence of MS among young patients with STEMI.

The present study found that patients with STEMI had a high prevalence of MS (46.8\%). In two previous studies, patients aged $<45$ years with STEMI or NSTEMI were evaluated, and the prevalence of MS was $40.4 \%{ }^{[9]}$ and $46.0 .{ }^{[10]}$ In a previous Turkish study, 217 patients (mean age at baseline $49.1 \pm 13$ years) with CAD, the prevalence of MS was reported $53 \% .^{[11]}$ The other studies reported the prevalence of MS in ACS $29 \%-66 \% .^{[5,6,12-14]}$ In a cross-sectional study, prevalence of MS was found $49.7 \%$ among adult patients who admitted to cardiology department. ${ }^{[14]}$ In another study, 1255 patients aged 65 years old and over without any acute illness were evaluated, and prevalence of MS was reported $23.8 \% .^{[15]}$

When the twenty patients with DM were excluded, 51 of the remaining $121(42.1 \%)$ have $>3$ criteria for MS. The other studies found the prevalence of MS among the patients with ACS without DM, 34\% ${ }^{[5]}$ and $42 \% .^{[10]}$
The average value for criteria of MS (TG, systolic and diastolic blood pressure, fasting plasma glucose, and WC) were all significantly higher in patients with MS compared with those without but no significant difference was observed between two groups for HDLc and LDLc levels. Multiple epidemiological studies have demonstrated that HDLc concentrations are inversely and independently associated with the development of ischemic heart disease, ${ }^{[2]}$ and hence, in our study prevalence of low HDLc level was seen very common in all groups. Statistical significance between patients with and without MS was maintained even when patients with known or newly diagnosed DM excluded. At the same time, low HDLc level was most frequent component of MS, followed by elevated TG [Figure 1]. The ATPIII concluded that low HDLc concentrations and high TG levels are cardiovascular risk factors, regardless of LDLc levels. ${ }^{[1]}$ And, they are found very common in young patients with STEMI, but the first target is LDLc level according to current guidelines in all ages. ${ }^{[2,16]}$

The most frequent triad combination of MS was impaired glucose tolerance, low HDLc level and elevated TG in the MS group without excluding DM. In a retrospective study of 574 patients with ACS, low HDLc, elevated blood pressure and impaired glucose tolerance were found to be the most frequent triad of MS. ${ }^{[5]}$

Perez et al. reported that fibrinogen and C-reactive protein (CRP) levels were significantly higher in adults with MS than without MS. ${ }^{[17]}$ Differently, in this study fibrinogen levels were found significantly higher in patients with MS and there was no significant difference between two groups in the level of CRP and D-dimer. But, in our study, all patients with STEMI and CRP and D-dimer levels could be increased due to STEMI in both groups. In a case-control study, 220 patients with ACS were compared with 116 healthy volunteers, and ACS cases showed 4-fold higher median CRP concentration on admission than healthy controls. ${ }^{[18]}$ However, the d-dimer level was found to be higher among patients with ACS.$^{[19-24]}$ In another previous study, 2722 nondiabetic men aged 60-79 years with no history of CAD were determined, and insulin resistance was found significantly associated with increased CRP, but the association with fibrinogen and fibrin d-dimer were found weak. ${ }^{[25]}$

Among our patients, single-vessel involvement with LAD was the most frequent culprit lesion within both groups. Colkesen et al. reported characteristics of STEMI in young patients aged $<35$. They reported that young patients with acute STEMI showed a preponderance of single-vessel disease and acute anterior STEMI owing to occluded LAD artery. ${ }^{[26]}$

In our study, there was no relationship between MS and the number of vessels affected. However, Marso et al. determined plaque composition of 673 patients with ACS and lesion length, plaque burden, necrotic core, and calcium content were significantly greater among nonculprit lesions of patients with diabetes or MS. ${ }^{[27]}$ Furthermore, Yoon et al. found relationship between MS score and severity of coronary atherosclerosis. ${ }^{[28]}$ 
In both studies, the assessment of vessels was different and more detailed than our study.

Another study included 100 patients with STEMI, and 40\% of these patients have MS based on Consensus statement for diagnosis of MS for Asian Indians, 49\% had anterior wall MI and $37 \%$ had inferior wall MI. ${ }^{[29]}$ In the different data that study population consisted of 467 men admitted with ACS. A total of $324(69.37 \%)$ patients fulfilled the criteria stated in the latest joint statement for the definition of MS. ${ }^{[8]}$ Among them, STEMI was present in $178(54.9 \%)$ patients and NSTE-ACS in 146 (45.1\%) patients ( $P$ value, nonsignificant). There was also no significant difference in the prevalence of different types of ACS between the MS and non-MS groups (STEMI, 54.9\% vs. 51.7\%; NSTE-ACS, $45.1 \%$ vs. $48.3 \%$, respectively; $P=0.294$ for both). ${ }^{[30]}$

\section{Conclusions}

This study revealed that the prevalence of MS in young patients with STEMI is high. Moreover, the most common criteria of MS are low HDLc and followed by elevated TG. Finally, the prevalence of MS is increasing worldwide, and it influences all age groups, and hence, these results highlight the need to implement preventative strategies for reducing overall cardiovascular risks in young patients as well as elderly.

\section{Limitations}

The study had several limitations. First, this is a single-center study. Moreover, second, unfortunately, we could not sought to examine the long-term clinical outcomes of all patients. Moreover, third, in our study, the assessment of vessels lesions was not detailed in both groups.

\section{Financial support and sponsorship}

Nil.

\section{Conflicts of interest}

There are no conflicts of interest.

\section{RefEREnCES}

1. Expert Panel on Detection, Evaluation, and Treatment of High Blood Cholesterol in Adults. Executive summary of the third report of the national cholesterol education program (NCEP) expert panel on detection, evaluation, and treatment of high blood cholesterol in adults (Adult treatment panel III). JAMA 2001;285:2486-97.

2. Ibanez B, James S, Agewall S, Antunes MJ, Bucciarelli-Ducci C, Bueno H, et al. 2017 ESC guidelines for the management of acute myocardial infarction in patients presenting with ST-segment elevation: The task force for the management of acute myocardial infarction in patients presenting with ST-segment elevation of the European Society of Cardiology (ESC). Eur Heart J 2018;39:119-77.

3. Piepoli MF, Hoes AW, Agewall S, Albus C, Brotons C, Catapano AL, et al. 2016 European guidelines on cardiovascular disease prevention in clinical practice: The sixth joint task force of the European society of cardiology and other societies on cardiovascular disease prevention in clinical practice (constituted by representatives of 10 societies and by invited experts) Developed with the special contribution of the European association for cardiovascular prevention and rehabilitation (EACPR). Eur Heart J 2016;37:2315-81.

4. Choudhury L, Marsh JD. Myocardial infarction in young patients. Am J Med 1999;107:254-6.
5. Jover A, Corbella E, Muñoz A, Millán J, Pintó X, Mangas A, et al. Prevalence of metabolic syndrome and its components in patients with acute coronary syndrome. Rev Esp Cardiol 2011;64:579-86.

6. Al-Rasadi K, Sulaiman K, Panduranga P, Al-Zakwani I. Prevalence, characteristics, and in-hospital outcomes of metabolic syndrome among acute coronary syndrome patients from Oman. Angiology 2011;62:381-9.

7. Fiuza M, Cortez-Dias N, Martins S, Belo A; VALSIM study investigators. Metabolic syndrome in Portugal: Prevalence and implications for cardiovascular risk - Results from the VALSIM study. Rev Port Cardiol 2008;27:1495-529.

8. Thygesen K, Alpert JS, Jaffe AS, Simoons ML, Chaitman BR, White HD, et al. Third universal definition of myocardial infarction. Eur Heart J 2012;33:2551-67.

9. Milionis HJ, Kalantzi KJ, Papathanasiou AJ, Kosovitsas AA, Doumas MT, Goudevenos JA, et al. Metabolic syndrome and risk of acute coronary syndromes in patients younger than 45 years of age. Coron Artery Dis 2007; 18:247-52.

10. Chung EH, Curran PJ, Sivasankaran S, Chauhan MS, Gossman DE, Pyne CT, et al. Prevalence of metabolic syndrome in patients $<$ or $=45$ years of age with acute myocardial infarction having percutaneous coronary intervention. Am J Cardiol 2007;100:1052-5.

11. Onat A, Sansoy V. Metabolic syndrome, major culprit of coronary disease among Turks: Its prevalence and impact on coronary risk. Arch Turk Soc Cardiol 2002;30:8-15.

12. Clavijo LC, Pinto TL, Kuchulakanti PK, Torguson R, Chu WW, Satler LF, et al. Metabolic syndrome in patients with acute myocardial infarction is associated with increased infarct size and in-hospital complications. Cardiovasc Revasc Med 2006;7:7-11.

13. Levantesi G, Macchia A, Marfisi R, Franzosi MG, Maggioni AP, Nicolosi GL, et al. Metabolic syndrome and risk of cardiovascular events after myocardial infarction. J Am Coll Cardiol 2005;46:277-83.

14. Kalantzi K, Korantzopoulos P, Tzimas P, Katsouras CS, Goudevenos JA, Milionis HJ, et al. The relative value of metabolic syndrome and cardiovascular risk score estimates in premature acute coronary syndromes. Am Heart J 2008;155:534-40.

15. Cankurtaran M, Halil M, Yavuz BB, Dagli N, Oyan B, Ariogul S, et al. Prevalence and correlates of metabolic syndrome (MS) in older adults. Arch Gerontol Geriatr 2006;42:35-45.

16. Catapano AL, Graham I, Backer GD, Wiklund O, Chapman MJ, Drexel H, et al. 2016 ESC/EAS guidelines for the management of dyslipidaemias. Eur Heart J 2016;37:2999-3058.

17. Pérez CM, Ortiz AP, Guzmán M, Suárez E. Distribution and Correlates of the Metabolic Syndrome in Adults Living in the San Juan Metropolitan Area of Puerto Rico. P R Health Sci J 2012;31:114-22.

18. Krintus M, Kozinski M, Stefanska A, Sawicki M, Obonska K, Fabiszak T, et al. Value of C-reactive protein as a risk factor for acute coronary syndrome: A comparison with apolipoprotein concentrations and lipid profile. Mediators Inflamm 2012;2012:419804.

19. Tokita Y, Kusama Y, Kodani E, Tadera T, Nakagomi A, Atarashi H, et al. Utility of rapid D-dimer measurement for screening of acute cardiovascular disease in the emergency setting. J Cardiol 2009;53:334-40.

20. Shitrit D, Bar-Gil Shitrit A, Rudensky B, Sulkes J, Tzviony D. Determinants of ELISA D-dimer sensitivity for unstable angina pectoris as defined by coronary catheterization. Am J Hematol 2004;76:121-5.

21. Shitrit D, Bar-Gil Shitrit A, Rudensky B, Sulkes J, Gutterer N, Zviony D, et al. Role of ELISA D-dimer test in patients with unstable angina pectoris presenting at the emergency department with a normal electrocardiogram. Am J Hematol 2004;77:147-50.

22. Bayes-Genis A, Mateo J, Santaló M, Oliver A, Guindo J, Badimon L, et al. D-dimer is an early diagnostic marker of coronary ischemia in patients with chest pain. Am Heart J 2000;140:379-84.

23. Kruskal JB, Commerford PJ, Franks JJ, Kirsch RE. Fibrin and fibrinogen-related antigens in patients with stable and unstable coronary artery disease. N Engl J Med 1987;317:1361-5.

24. Empana JP, Canoui-Poitrine F, Luc G, Juhan-Vague I, Morange P, Arveiler D, et al. Contribution of novel biomarkers to incident stable angina and acute coronary syndrome: The PRIME study. Eur Heart J 2008;29:1966-74. 
25. Wannamethee SG, Lowe GD, Shaper AG, Rumley A, Lennon L, Whincup PH, et al. The metabolic syndrome and insulin resistance: Relationship to haemostatic and inflammatory markers in older non-diabetic men. Atherosclerosis 2005;181:101-8.

26. Colkesen AY, Acil T, Demircan S, Sezgin AT, Muderrisoglu H. Coronary lesion type, location, and characteristics of acute ST elevation myocardial infarction in young adults under 35 years of age. Coron Artery Dis 2008;19:345-7.

27. Marso SP, Mercado N, Maehara A, Weisz G, Mintz GS, McPherson J, et al. Plaque composition and clinical outcomes in acute coronary syndrome patients with metabolic syndrome or diabetes. JACC Cardiovasc Imaging 2012;5:S42-52.

28. Yoon SE, Ahn SG, Kim JY, Park JS, Shin JH, Tahk SJ, et al.
Differential relationship between metabolic syndrome score and severity of coronary atherosclerosis as assessed by angiography in a non-diabetic and diabetic Korean population. J Korean Med Sci 2011;26:900-5.

29. Uppalakal B, Karanayil LS. Incidence of metabolic syndrome in patients admitted to medical wards with ST elevation myocardial infarction. J Clin Diagn Res 2017;11:OC17-20.

30. Al-Aqeedi RF, Abdullatef WK, Dabdoob W, Bener A, Albinali HA, Gehani A, et al. The prevalence of metabolic syndrome components, individually and in combination, in male patients admitted with acute coronary syndrome, without previous diagnosis of diabetes mellitus. Libyan J Med 2013;8:20185. 